\title{
Synthesis and structural characterization of calcium titanate by spray pyrolysis method
}

\author{
S. Lanfredi ${ }^{\text {a,* }}$, F. Storti ${ }^{\text {a }}$, L.P.M. Simões ${ }^{a}$, E. Djurado ${ }^{\text {b,c }}$, M.A.L. Nobre ${ }^{\text {a }}$ \\ a São Paulo State University (Unesp), School of Technology and Sciences, Presidente Prudente, Laboratory of Composites and Ceramics Functional - LaCCeF, P.O Box 467, \\ 19060-900, Brazil \\ ${ }^{\mathrm{b}}$ Univ. Grenoble Alpes, LEPMI, 1130 rue de la Piscine, F-38402 St Martin d'Hères, France \\ ${ }^{\mathrm{c}}$ CNRS, LEPMI, F-38000 Grenoble, France
}

\section{A R T I C L E I N F O}

\section{Article history:}

Received 2 December 2016

Accepted 1 May 2017

Available online 2 May 2017

\section{Keywords:}

Chemical synthesis

Spray pyrolysis method

Calcium titanate

Rietveld method

\begin{abstract}
A B S T R A C T
Single phase and crystalline calcium titanate exhibiting spherical particle was synthesized by spray pyrolysis method. Nanometric to submicrometric particle size was characterized by X-ray diffraction and scanning electron microscopy. Crystalline structure and its crystallographic parameters were investigated via Rietveld method. The spray was generated from aqueous solution. An acid solution was tailored to support titanium IV isopropoxide as source of titanium cation. The acid character of the solution is reached from addition of citric acid monohydrate. Calcium nitrate was used as source of calcium. The influence of the precursor solution concentration and furnace temperature on the crystallization phenomenon of the calcium titanate was investigated. $\mathrm{CaTiO}_{3}$ exhibits orthorhombic symmetry and space group Pbnm ( $\mathrm{a}=5.3862 \AA, \mathrm{b}=5.4433 \AA$ and $\left.\mathrm{c}=7.6440 \AA, \mathrm{V}=224.11 \AA^{3}\right)$. Nanostructure development is discussed.
\end{abstract}

(c) 2017 Elsevier B.V. All rights reserved.

\section{Introduction}

Perovskite $\mathrm{ABO}_{3}$ oxides represent a major class of crystalline oxides and are known to exhibit properties such as giant magnetoresistance, high-Tc superconductivity, metal-insulator transitions [1]. The rich diversity of chemical and physical properties of this structure is derived from its ability to accommodate various metal elements at both the A and B sites with a wide range of ionic radius and valence. Among the class of perovskite structure oxides stands out the $\mathrm{CaTiO}_{3}$. Calcium titanate is an important material, being used as basis to obtain new materials in many research fields $[2,3]$. This material exhibits high dielectric constant, low dielectric loss and large temperature coefficient of resonant frequency, which makes it a promising component in the production of communication equipment operating at microwave frequencies [4]. As a matter of fact, these properties depend on the powders morphology and the method of synthesis. Up until now, various methods have been reported in the literatures for the syntheses of $\mathrm{CaTiO}_{3}$. Among these methods include conventional solid state [5], chemical co-precipitation method [6], hydrothermal method [7], sol-gel route [8] and polymeric precursor method [9]. In this work the $\mathrm{CaTiO}_{3}$ has been synthesized by spray pyrolysis method, where

\footnotetext{
* Corresponding author.

E-mail address: silvania@fct.unesp.br (S. Lanfredi).
}

the influence of processing parameters on the crystallization phenomenon has been investigated. This method allows to obtain material with high chemical and structural homogeneity, containing grains with controlled morphology and size [10].

\section{Experimental}

\subsection{Synthesis}

$\mathrm{CaTiO}_{3}$ nanoparticles were prepared by spray-pyrolysis method [10]. The precursor solution of the $\mathrm{CaTiO}_{3}$ was prepared from a stoichiometric mixture of titanium IV isopropoxide with citric acid monohydrate and calcium nitrate. The titanium precursor solution was prepared from the reaction of citric acid and titanium IV isopropoxide with the molar ratio $3: 1$ and heating at $70^{\circ} \mathrm{C}$. The concentrations investigated were $0.025 \mathrm{~mol} . \mathrm{L}^{-1}, 0.05 \mathrm{~mol} . \mathrm{L}^{-1}$ and $0.1 \mathrm{~mol} . \mathrm{L}^{-1}$. The solutions were placed in the spray container and were atomized by a high frequency ultrasonic generator of 1.7 $\mathrm{MHz}$. The aerosol generated was drawn into a tubular furnace, using a carrier gas constituted of $\mathrm{N}_{2}$ and $\mathrm{O}_{2}$ with flow rate of $3 \mathrm{~L}$. $\mathrm{mim}^{-1}$. The pyrolysis furnace was programmed between $750{ }^{\circ} \mathrm{C}$ and $850^{\circ} \mathrm{C}$. Different experiments were performed in according to Table 1 . The average crystallite size was derived by Scherrer's equation. 


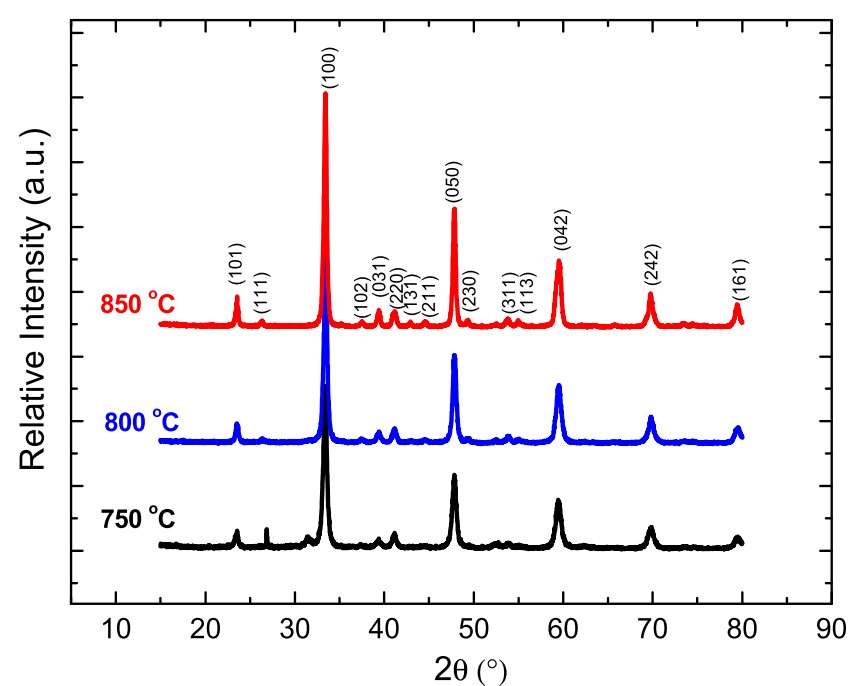

Fig. 1. XRD patterns of $\mathrm{CaTiO}_{3}$ powders obtained from the precursor solution concentration of $0.05 \mathrm{~mol} . \mathrm{L}^{-1}$ in air flow of $3 \mathrm{~L} / \mathrm{min}$.

\subsection{Structural characterization}

Structural characterization of the $\mathrm{CaTiO}_{3}$ was carried out by Xray diffraction (XRD). A diffractometer XRD-6000 (Shimadzu model) with $\mathrm{Cu}-\mathrm{K} \alpha$ radiation $(\lambda=1.54 \AA)$ and a graphite monochromator were used. Measurements were carried out over an angular range of $5^{\circ} \leq 2 \theta \leq 80^{\circ}$ with a scanning step of $0.02^{\circ}$. The structure was refined according to the Rietveld method using the Fullprof program [11].

The average crystallite size values of the powders obtained from solutions prepared by spray pyrolysis are shown in Table 1 . The powder morphology was analyzed by scanning electron microscopy (SEM) using a microscope model Carls Zeiss EVO LS15, operating at $30 \mathrm{kV}$.

\section{Results and discussion}

Fig. 1 shows, as an example, the XRD patterns of $\mathrm{CaTiO}_{3}$ powders obtained by spray pyrolysis method with solution concentration equal to $0.05 \mathrm{~mol} . \mathrm{L}^{-1}$, air flow of $3 \mathrm{~L} / \mathrm{min}$ and at temperatures of $750{ }^{\circ} \mathrm{C}, 800^{\circ} \mathrm{C}$ and $850^{\circ} \mathrm{C}$. The X-ray diffraction, for all experimental conditions investigated, showed only a set of diffraction lines ascribed to $\mathrm{CaTiO}_{3}$ single phase powders, which were identified from the JCPDS card number 78-1013.

The structural parameter set of the $\mathrm{CaTiO}_{3}$ powders was derived using the Rietveld method. The refinements were performed by taking into account the space group Pbnm (62) compatible with orthorhombic symmetry. In the refined structure the assigned occupation sites were $4 \mathrm{c}$ for $\mathrm{Ca} / \mathrm{O} 1,4 \mathrm{~b}$ for $\mathrm{Ti}$ and $8 \mathrm{~d}$ for $\mathrm{O}_{2}$.

The Fig. 2(a) shows the graphic representation of the unit cell of $\mathrm{CaTiO}_{3}$ powder obtained from solution concentration equal to $0.05 \mathrm{~mol} . \mathrm{L}^{-1}$, air flow of $3 \mathrm{~L} / \mathrm{min}$ and at temperature of $850{ }^{\circ} \mathrm{C}$. Titanium atoms occupy distorted 6-fold coordinated sites in the structure and the Ca cations occupy the 12-fold cuboctahedral coordination. Fig. 2(b) shows tilted and distorted TiO6 octahedra view along (001), which can be observed from the angle values between $\mathrm{Ti}-\mathrm{O}-\mathrm{Ti}$ and $\mathrm{Ti}-\mathrm{O}$ bond distances. The rotation angle around the c-axis ( $\mathrm{Ti}-\mathrm{O} 2-\mathrm{Ti}$ ) is $155.630^{\circ}$, while the octahedral tilt angle relative to (001) plane is equal to $157.191^{\circ}$, showing the distortion of octahedra. The TiO6 polyhedra exhibit a similar distortion to that reported in literature [12].

The powder morphology was analyzed by scanning electron microscopy (SEM). Fig. 3 shows, as an example, the morphology of the powders obtained in experiments 1 and Fig. 4 shows the powder morphology obtained in experiment 9 (Table 1 ). In experiment 1 the particles present spherical shape and smooth surface,

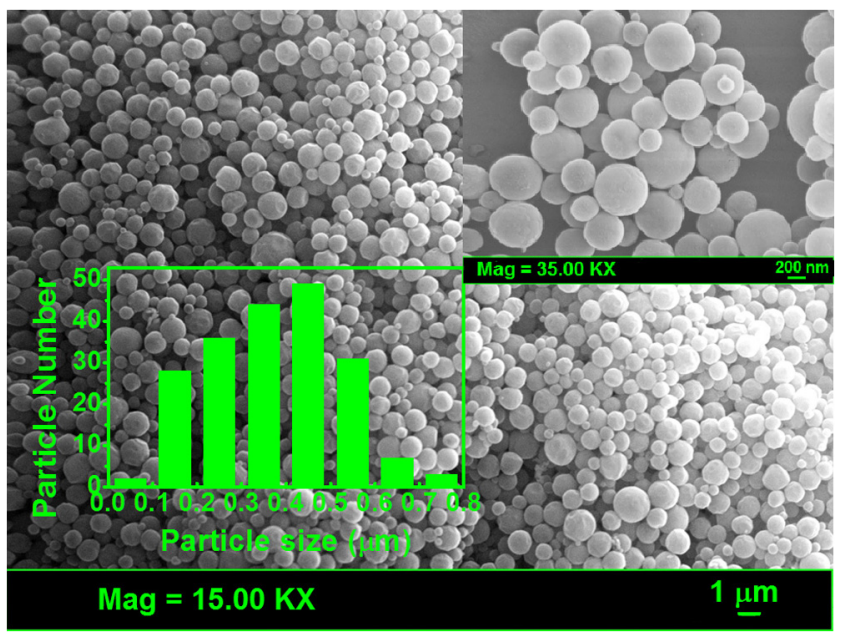

Fig. 3. Scanning electron microscopy (SEM) of powders obtained in Experiment 1.

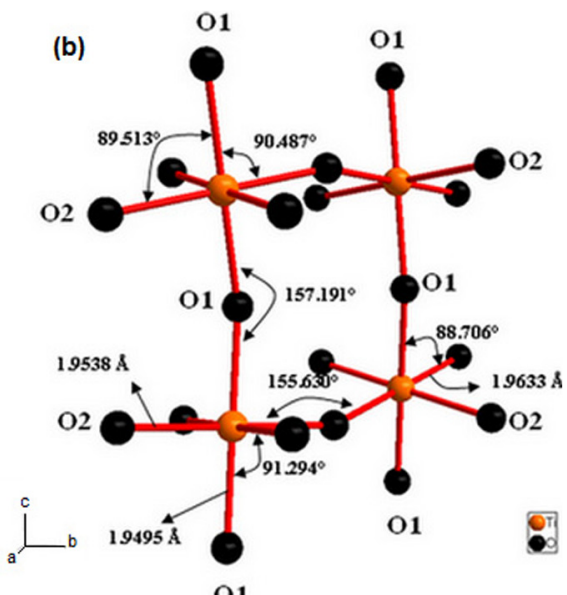

Fig. 2. (a) Unit cell of the $\mathrm{CaTiO}_{3}$ and (b) bond distances view along (001) axis. 
Table 1

Experimental conditions and average crystallite sizes for $\mathrm{CaTiO}_{3}$ powders.

\begin{tabular}{llll}
\hline Experiments & $\begin{array}{l}\text { Concentration } \\
\left(\mathrm{mol} . \mathrm{L}^{-1}\right)\end{array}$ & $\begin{array}{l}\text { Temperature } \\
\left({ }^{\circ} \mathrm{C}\right)\end{array}$ & $\begin{array}{l}\text { Average crystallite } \\
\text { size }(\mathrm{nm})\end{array}$ \\
\hline 1 & 0.025 & 750 & 5.7 \\
2 & 0.025 & 800 & 8.3 \\
3 & 0.025 & 850 & 8.7 \\
4 & 0.05 & 750 & 8.7 \\
5 & 0.05 & 800 & 9.0 \\
6 & 0.05 & 850 & 9.3 \\
7 & 0.1 & 750 & 8.7 \\
8 & 0.1 & 800 & 8.9 \\
9 & 0.1 & 850 & 9.2 \\
\hline
\end{tabular}

which were obtained with low solution concentration $\left(2.5 \times 10^{-2}\right.$ mol. $\mathrm{L}^{-1}$ ), see inset of Fig. 3. However, with increasing temperature, the particles show some degree of distortion. Furthermore, the increase of the solution concentration $\left(5 \times 10^{-2}\right.$ mol. $\left.\mathrm{L}^{-1}\right)$ showed a modification in the particle surface, where a large part of them presented an aspect rough. This phenomenon can be related with the solvent evaporation rate [13], where the evaporation stage can be associate as a series the physical phenomena occurring simultaneously. Thus, it was observed that the particles formed with higher concentration of the precursor solution presented high heterogeneity in the distribution of the particles size and more agglomerates. High concentration of the initial solution increases the droplet density which is thereby submitted to high internal stress during particle formation. The rapid evaporation of the solvent from the droplet surface can lead to the formation of a salt crust around the particles [12], as shown in Fig. 4 for the precursor solution concentration of $0.1 \mathrm{~mol} . \mathrm{L}^{-1}$. From the three concentrations investigated the solution of lower concentration $\left(2.5 \times 10^{-2}\right.$ mol. $\mathrm{L}^{-1}$ ) showed a greater amount of small particles, at around $0.4 \mu \mathrm{m}$. However, for high concentration of the precursor solutions $\left(5 \times 10^{-2} \mathrm{~mol} . \mathrm{L}^{-1}\right.$ and $\left.0.1 \mathrm{~mol} . \mathrm{L}^{-1}\right)$ large amount of particle size ranged between $0.6 \mu \mathrm{m}$ and $0.8 \mu \mathrm{m}$.

\section{Conclusions}

From the spray pyrolysis method was possible to obtain single and nanometric to submicrometric particle size of calcium titanate with the space group Pbnm and orthorhombic symmetry. The tests performed at different concentrations and temperature have shown that the concentration of the precursor solutions influence on the morphology of the particles. The morphological analysis of the powders showed that the $\mathrm{CaTiO}_{3}$ powders obtained from solution concentration of $2.5 \times 10^{-2} \mathrm{~mol} . \mathrm{L}^{-1}$, air flow of $3 \mathrm{~L} / \mathrm{min}$ and at $750{ }^{\circ} \mathrm{C}$ presented spherical and small particles with smooth surface, small agglomerates and lower average crystallite size, equal to $5.7 \mathrm{~nm}$, showing to be a promising catalyst.

\section{Acknowledgments}

The authors are grateful to the Brazilian research agencies: FAPESP, CNPq and UNESP/PROPe for financial support.

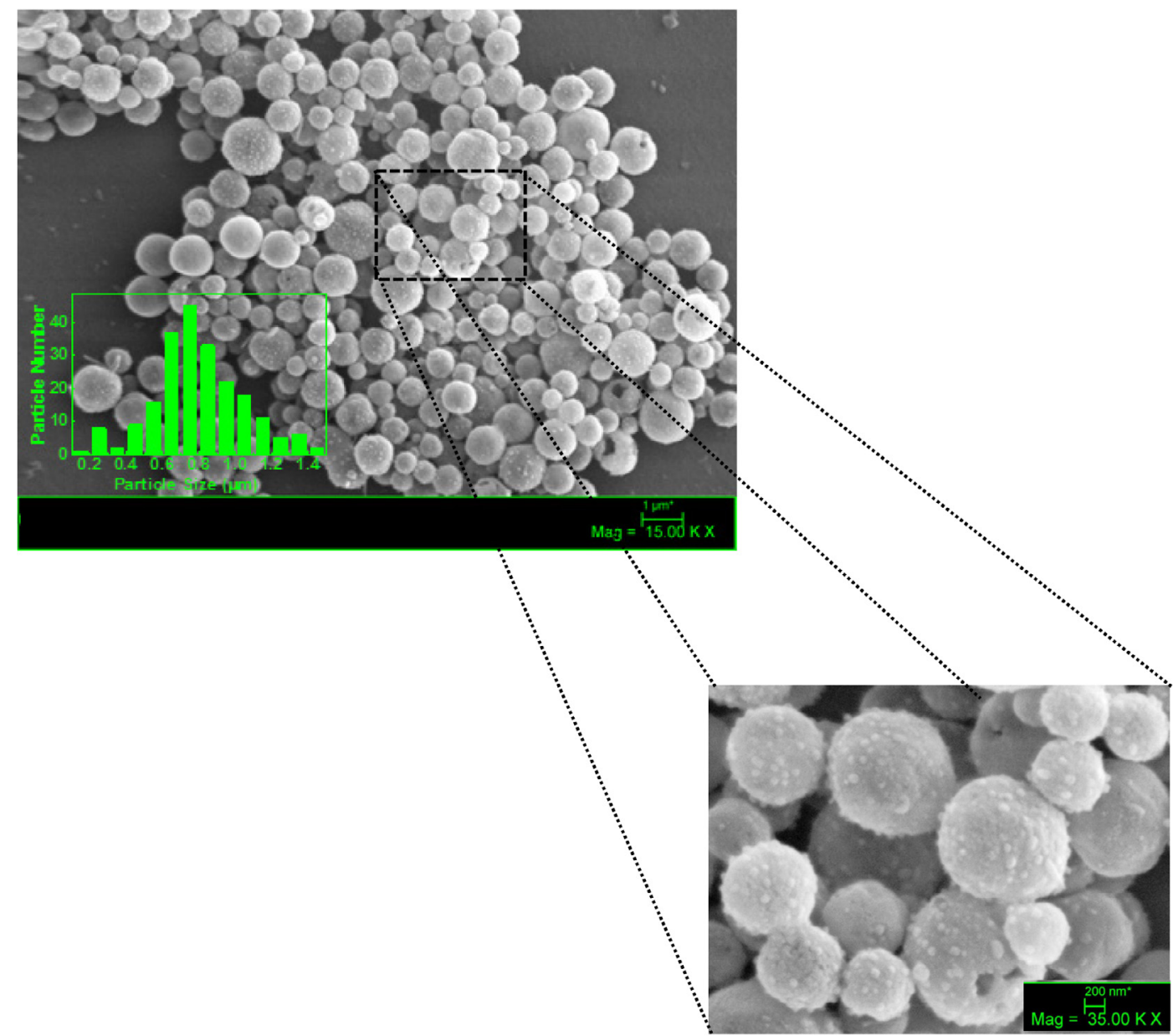

Fig. 4. Scanning electron microscopy (SEM) of powders obtained in Experiment 9. 


\section{References}

[1] Y. Moritomo, A. Asamitsu, H. Kuwahara, Y. Tokura, Nature 380 (1996) 141 144.

[2] X.S. Wang, C.N. Xu, H. Yamada, K. Nishikubo, X.G. Zheng, Adv. Mater. 17 (2005) $1254-1258$.

[3] H.N. Lee, H.M. Christen, M.F. Chisholm, C.M. Rouleau, D.H. Lowndes, Nature 433 (2005) 395-399.

[4] I.R. Evans, J.A.K. Howard, T. Sreckovic, M.M. Ristic, Mater. Res. Bull. 38 (2003) $1203-1213$.

[5] N.S. Rogado, J. Li, A.W. Sleight, M.A. Subramanian, Adv. Mater. 17 (2005) 2225 2227.

[6] M.H.S. Gopalakrishna, M. Subbarao, T.R. Narayan Kutty, Thermochim. Acta 13 (1975) 183-191.
[7] D.A. Wang, Z.G. Guo, Y.M. Chen, J.C. Hao, W.M. Lin, Inorg. Chem. 46 (2007) 7707-7711.

[8] S. Holliday, A. Stanishevsky, Surf. Coat. Technol. 188 (2004) 741-744.

[9] Y.X. Pan, Q. Su, H.F. Xu, T.H. Chen, W.K. Ge, C.L. Yang, M.M. Wu, J. Solid State Chem. 174 (2003) 69-74.

[10] E. Djurado, E. Meunier, J. Solid State Chem. 141 (1998) 191-198.

[11] J.R. Carvajal, An Introduction to the Program FullProff 2000, CEA/Saclay, France, 2008

[12] S. Sasaki, C.T. Prewitt, J.D. Bass, W.A. Schulze, Acta Crystallogr. C 43 (1987) 1668-1674.

[13] G.L. Messing, S.-C. Zhang, G.V. Jayanthi, J. Am. Ceram. Soc. 76 (1993) $2707-$ 2726. 